\title{
Introduction to the Special Issue "Super High Arch Dams and Underground Caverns in China"
}

\author{
Giovanni Barla ${ }^{1} \cdot$ Qixiang Fan ${ }^{2} \cdot$ Lin Peng $^{3}$
}

Published online: 19 July 2018

(c) Springer-Verlag GmbH Austria, part of Springer Nature 2018

China has a land area of about 9.6 million square kilometers and is crisscrossed by thousands of rivers. The rivers with drainage area greater than $1000 \mathrm{~km}^{2}$ are more than 1600 , while those with a drainage area greater than $100 \mathrm{~km}^{2}$ are more than 5000. Twenty rivers are longer than $1000 \mathrm{~km}$ each. The landform in China is high in the West and low in the East with great changes in elevation.

All the major rivers, such as Yangtze River, Yellow River, Lancang River and Nujiang River originate from the Qinghai-Tibet plateau, known as the "world roof". The difference in elevation between the headwater and river mouth is more than $5000 \mathrm{~m}$. The abundant runoff and high drop of the rivers make China a Country with a very high hydropower potential.

A dam is the most important indicator of flood control, water conservancy and hydropower development. As of 2014, China has built more than 98,000 reservoirs with a total storage capacity of $8,166 \times 10^{11} \mathrm{~m}^{3}$, accounting for $29 \%$ of the annual runoff of all rivers and streams. As shown in Fig. 1, before 1949, the dams in China higher than $15 \mathrm{~m}$ were only 22 . In the year 2000 , these dams were 24,000 to become more than 38,000 in 2013.

Dam and hydropower cavern construction in China has increased rapidly since the middle of the twentieth century and resulted in interesting and innovative research, mainly centered on the construction of a number of high arch dams, actually "super high arch dams" as called by the Chinese designers. For example, Fig. 2 shows 18 dams with dam height greater than $200 \mathrm{~m}$, designed and constructed in the last 20 years.

\section{Giovanni Barla}

Giovanni.barla@polito.it

Politecnico di Torino, Turin, Italy

2 China Three Gorges Corporation, Beijing, China

3 School of Civil Engineering, Tsinghua University, Beijing, China
Of particular importance and worth of mention is the successful completion of dams such as Ertan (240 m), Laxiwa (250 m), Xiaowan (294.5 m), Jinping I (305 m), and Xiluodu (285.5 m). A view of the Xiloudu dam is shown in Fig. 3. All these projects are associated with high steep slopes, large underground caverns or groups of caverns at great depth, including tunnels associated to them.

The increase in height and the individual complexity of these arch dams, the specific rock mass conditions along the abutments and at the foundation level posed indeed challenging design and construction problems. The need for novel, basic and applied research approaches, which indeed deserve attention in the field of rock mechanics and rock engineering, is pointed out.

The new dams and related underground caverns, presently under construction in China (see the Baihetan Project in Figs. 4, 5), including planning of a number of dams near the Himalayan region, bring new challenges and require progress in rock mechanics and rock engineering, also given the varying geological and rock mass conditions which are encountered at dam sites. In these cases, foundation excavation and reinforcement measures play an important role in dam safety.

It is with these thoughts in mind that on October 29, 2016, the First International Workshop "Sino-Dam 2016", with the main topic "Long-term Stability of High Dams" was held at the China Three Gorges Corporation Headquarters in Beijing. The workshop was organized under the initiative of the RMRE Journal, Tsinghua University, and China Three Gorges Corporation, which also acted as the main sponsor.

The workshop saw nearly 100 Participants. Keynote speakers were: Giovanni Barla (Politecnico di Torino, Torino), Nick Barton (Nick Barton and Associates, Oslo), Anil Chopra (University of California, Berkeley), Manchao $\mathrm{He}$ (China University of Mining and Technology, Beijing), Runqiu Huang (Chengdu University of Technology), Paul Marinos (National Technology University of Athens), Qihu 
Fig. 1 Dams in China with height greater than $15 \mathrm{~m}$ between 1950 and 2013

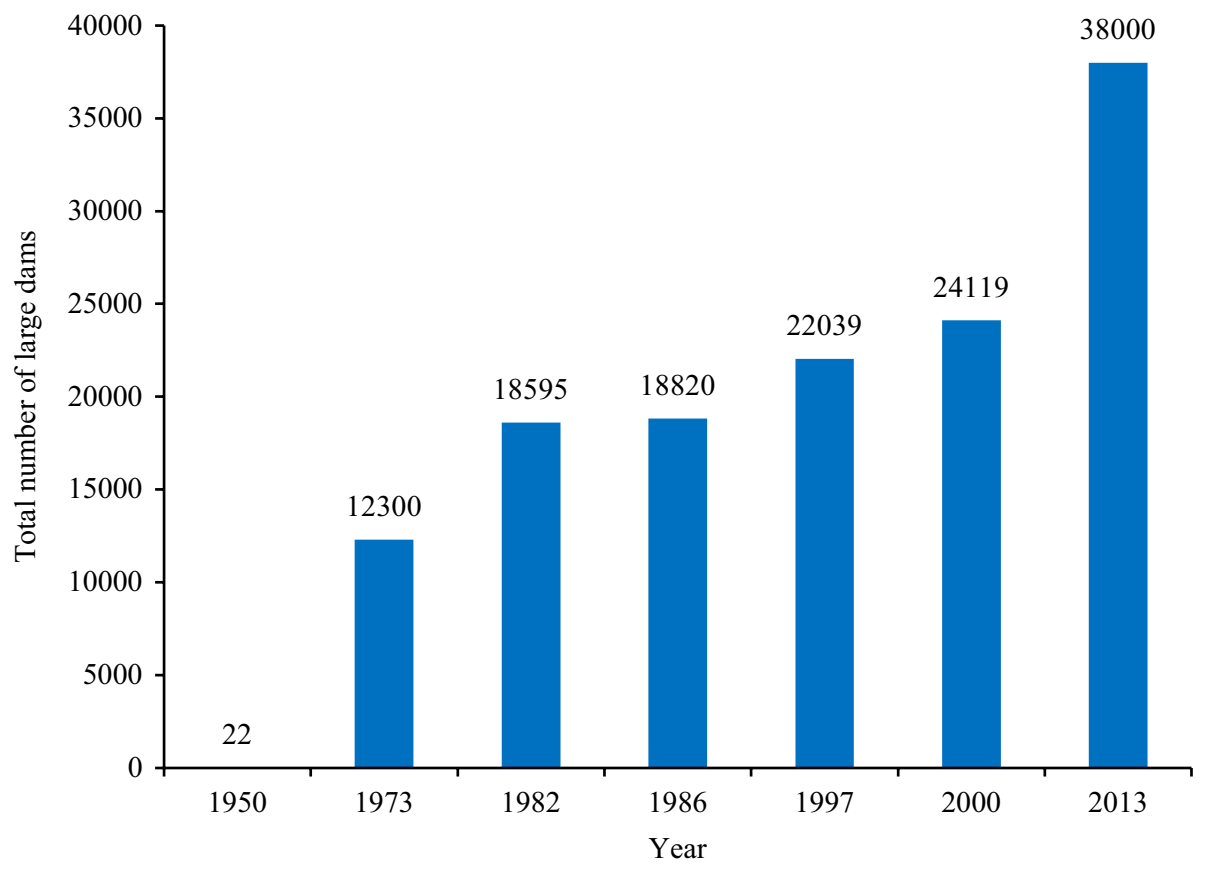

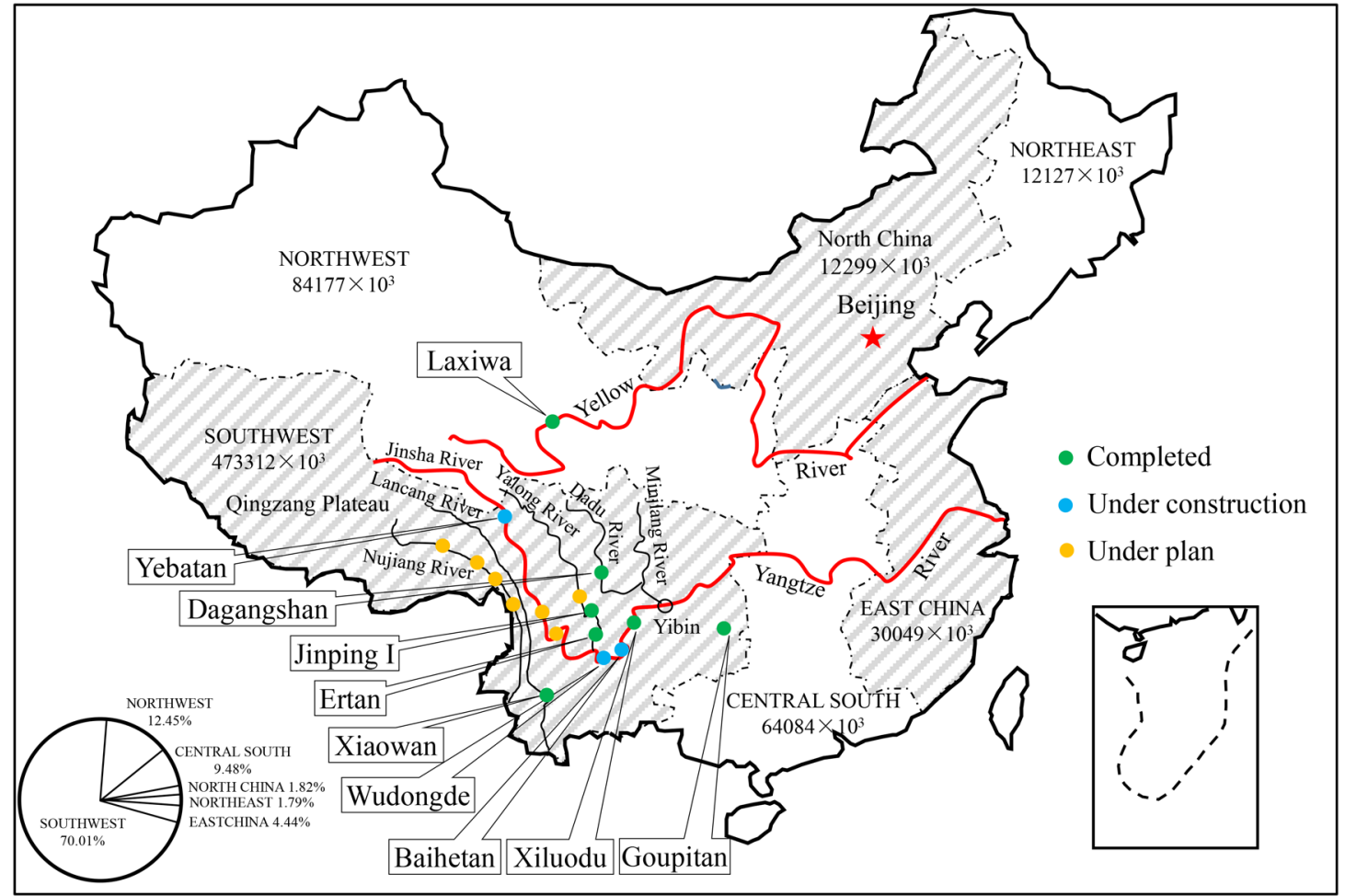

Fig. 2 Distribution of water resources and "super-high arch dams" in China 


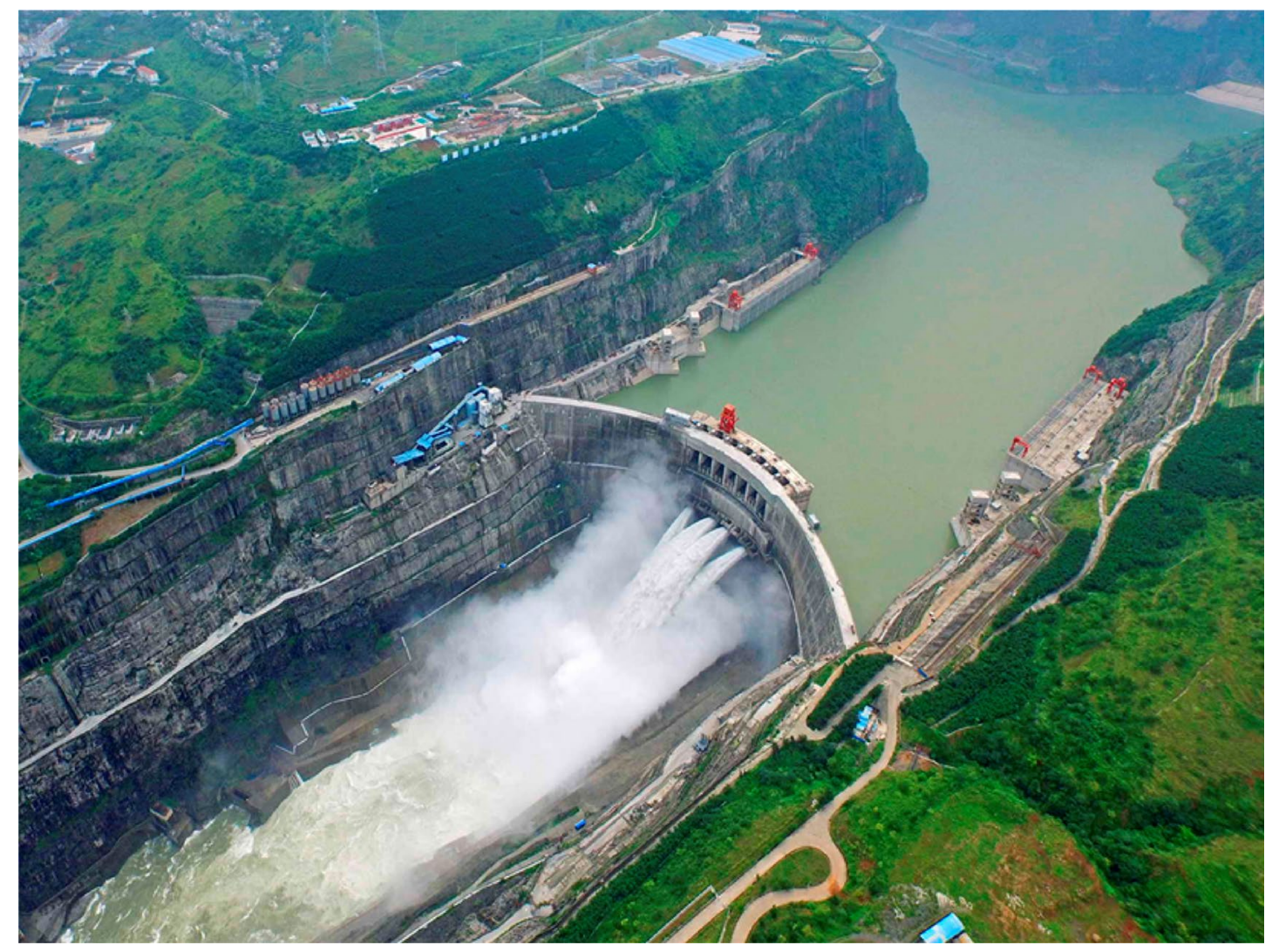

Fig. 3 A view of the Xiluodu arch dam in operation

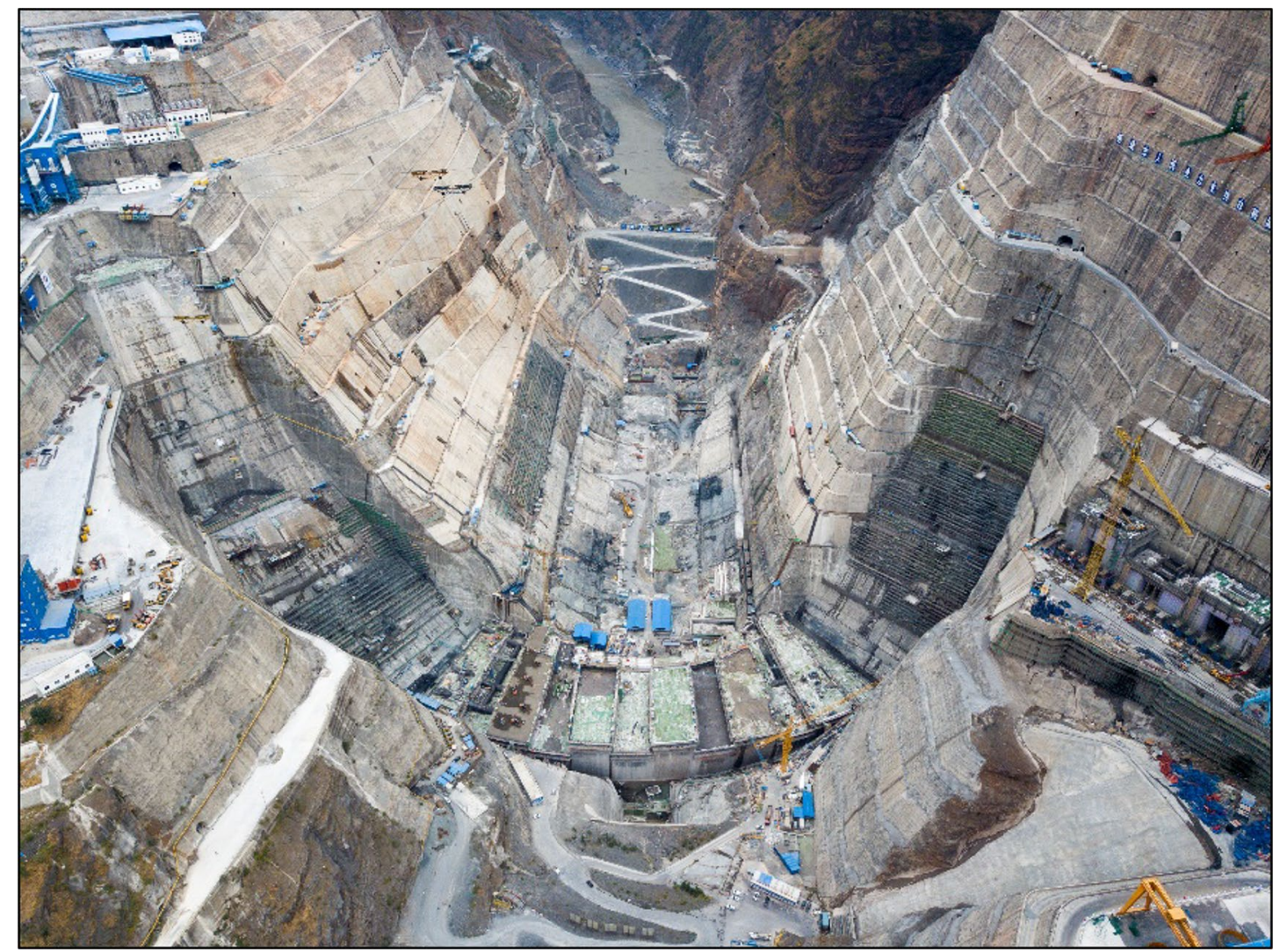

Fig. 4 The Baihetan "super-high arch dam" presently under construction 


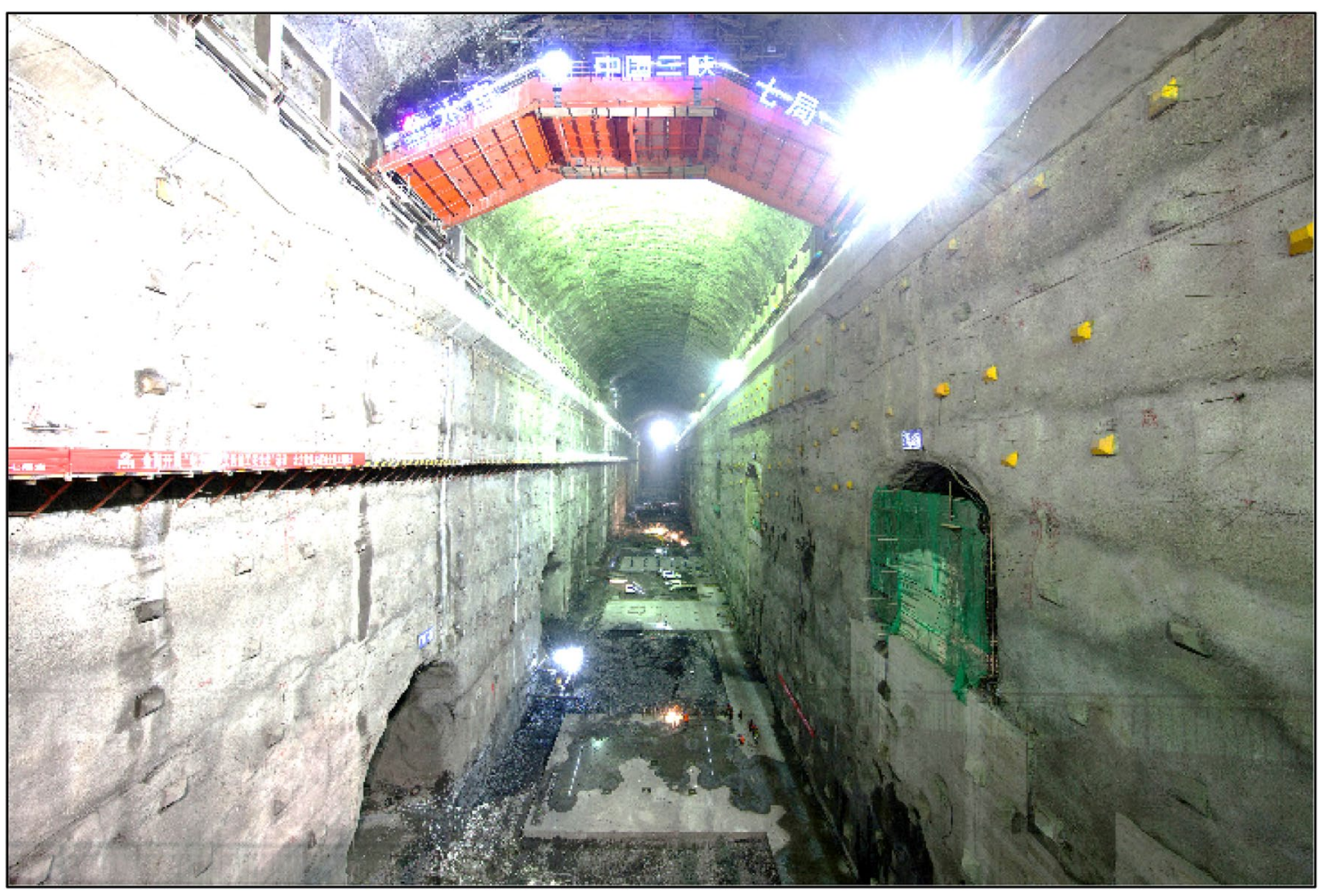

Fig. 5 The Baihetan powerhouse cavern presently under construction

Qian, (PLA University of Science and Technology, Nanjing), Chuan Zhang (Tsinghua University).

Recent trends and challenges in rock mechanics and rock engineering in the design and construction of high dams under extreme geological and geomechanical conditions were discussed. The main topics were In Situ Investigations and Field Monitoring, Excavation and Reinforcement, Impoundment and Operation, Reservoir Slopes and Caverns.

As a follow-up of the Workshop, the Editor of the RMRE Journal took the initiative to prepare a special issue containing papers on these topics, some of them based on the presentations given during the Workshop and some others submitted to the Journal following the Workshop. The original papers, accepted for publication according to the RMRE Journal review process, form the Special Issue "Super High Dams and Underground Caverns in China" which is published in this issue.

Publisher's Note Springer Nature remains neutral with regard to jurisdictional claims in published maps and institutional affiliations. 